\title{
БАЛАНС КОМПЕТЕНЦИЙ МЕЖДУ ВЕЛИКОБРИТАНИЕЙ И ЕС: ИТОГИ И ЗНАЧЕНИЕ ДЛЯ ПОЛИТИКИ ВЕЛИКОБРИТАНИИ
}

\author{
Е. О. ПАШКОВСКАЯ \\ Белорусский государственный университет \\ Минск, Республика Беларусь
}

В статье рассматривается проводившееся в 2012-2014 гг. в Великобритании исследование баланса компетенций с Европейским союзом (ЕС), его итоги и влияние на внешнюю политику Великобритании в отношении ЕС. Целью статьи является анализ результатов исследования правительства Великобритании и их влияние на политику государства в отношении ЕС. Для рассмотрения были выбраны следующие области совместных компетенций Соединенного Королевства и ЕС: предоставление убежища и иммиграционная политика в отношении государств, не входящих в союз, выплаты в бюджет ЕС, свободное перемещение по странам союза. Автором был проведен критический анализ отчетов в данных сферах, выявлена степень их значимости при формировании политики Великобритании в отношении ЕС. Данное исследование является одним из первых исследований, затрагивающих вопросы проведения анализа компетенций между Великобританией и ЕС в русскоязычной историографии. Автор отмечает, что в области иммиграции, свободного передвижения и выплат в бюджет ЕС исследование показало преобладание британской компетенции и соответствие интересам государства. Тем не менее, Д. Кэмерон не учитывал результатов исследования для принятия внешнеполитических решений, а баланс компетенций был инициирован не с целью получить объективные факты о текущем положении дел между Великобританией и ЕС, а лишь для того, чтобы продемонстрировать британские намерения изменить отношения с ЕС. Итоги баланса компетенций не были учтены во внешней политике в отношении ЕС, а также не стали известны широкой общественности, что продемонстрировало несоответствие целей проведения исследования решениям правительства.

Ключевые слова: Соединенное Королевство; Европейский Союз; баланс компетенций; коалиционное правительство; Брексит; Консервативная партия; Дэвид Кэмерон; иммиграция; свободное передвижение; система предоставления убежища.

Образец цитирования: Пашковская $E$. O. Баланс компетенций между Великобританией и ЕС: итоги и значение для политики Великобритании (20122014гг.) // Актуальные проблемы международных отношений и глобального 
развития: сб. науч. статей. Минск, 2020. Вып. 8. С. 88-102. https://doi.org/10.33581/2311-9470-2020-8-88-102

Введение. Баланс компетенций между Великобританией и ЕС масштабное исследование, начатое с целью проверки степени влияния ЕС на Соединённое Королевство в тех сферах, где государством были переданы некоторые полномочия союзу. За два года было выпущено 32 подробных отчёта, охватывающих определенную сферу деятельности государства, в которой его полномочия пересекались с полномочиями ЕС. Причин для проведения такого исследования было несколько. Последствия мирового экономического и финансового кризиса, глобализация, растущее чувство отчужденности Великобритании от процесса принятия решений в Брюсселе и связанный с этим рост поддержки евроскептически настроенных партий стали основными ${ }^{1}$. Они побудили многие европейские государства подвергнуть переоценке их отношения с ЕС.

Цель статьи - анализ результатов исследования баланса компетенций Великобритании с Европейским союзом и их влияние на политику государства в отношении ЕС.

Задачи: рассмотреть баланс компетенций между Великобританией и ЕС в области предоставления убежища, иммиграционной политики в отношении государств, не входящих в союз, выплат в бюджет ЕС, свободного перемещения по странам союза; выявить актуальность и степень практического применения проведенного исследования в политике Великобритании.

Хронологические рамки рассматриваемого вопроса - 20122014 гг., период проведения исследования баланса компетенций. На протяжении этого периода было подготовлено 32 отчета по различным сферам взаимодействия Великобритании и ЕС и дана оценка их компетенций.

Актуальность исследования обусловлена недостаточной освещенностью данного вопроса в русскоязычной и англоязычной историографии. Анализ результатов баланса компетенций и их влияния на политику Великобритании к ЕС позволяет сделать выводы об общей

\footnotetext{
${ }^{1}$ Review of the Balance of Competences between the United Kingdom and the European Union // HM Government [Electronic resource]. URL : https://assets.publishing.service.gov.uk/government/ uploads/system/uploads/attachment_data/file/35458/eu-balance-of-competences-review.pdf (accessed : 06.04.2020). p. 7-11.
} 
направленности отношений Соединенного Королевства и ЕС в обозначенный период.

Методы исследования. Объект исследования - отношения Великобритании и ЕС. Предмет исследования - влияние баланса компетенций между Великобританией и ЕС на британскую политику.

Для раскрытия темы использовалось сочетание общенаучных и специально-исторических методов. Среди общенаучных методов были использованы исторический и системный подход. Из общенаучных логических методов применялись анализ, синтез, индукция, дедукция, научное изучение и обобщение. В рамках исследования из специально-исторических методов задействованы историкогенетический и историко-описательный методы.

В процессе исследования итогов баланса компетенций большая роль уделялась критическому анализу изученных статей по рассматриваемой проблеме. В ходе исследования проводилось установление связи между различными элементами. Оно дополнялось частично аналитическим исследованием, направленным на установление причинно-следственных связей.

Обзор литературы по теме. Для написания статьи были изучены работы русскоязычных и англоязычных авторов.

Дж. Портес рассматривает историю свободного передвижения в $\mathrm{EC}$, в частности, результат принятого решения о незамедлительном вступлении принятых в 2004 г. государств на общий рынок труда. Автор также анализирует положения о пересогласовании условий членства в ЕС для Великобритании и связь свободного передвижения в рамках единого европейского рынка труда на референдум.

Е.В. Хахалкина изучает иммиграционную политику в период премьерства Д. Кэмерона. Исследователь отмечает большое количество мифов и стереотипов в британском обществе относительно миграции, в частности в период нахождения у власти коалиционного правительства. Такие убеждения, как большое количество иммигрантов в Великобритании, их нежелание работать, взаимосвязь повышения количества иммигрантов и влияния ЕС и др. во многом способствовали формированию негативного отношения к иммигрантам, хотя и не соответствовали действительности.

Дж. Деннисон и Э. Геддес рассматривали взаимосвязь Брексита и иммиграции из других государств - членов ЕС в Великобританию. В своем исследовании они изучили исторические и теоретические 
противоречия в британской миграционной политике и показали, как они помогли евроскептикам сформировать негативное отношение к иммигрантам и сделали иммиграцию одной из ключевых тем в британском обществе на протяжении последних двух десятилетий.

Д. Робинсон исследовал реформы коалиционного правительства Великобритании в сфере миграционной политики и вероятность выполнения правительством задачи по сокращению чистой миграции до менее чем 100 тыс. чел. и пришел к выводу, что данную цель британское правительство едва ли сможет достичь. Он также выявил ряд вопросов, требующих пристального внимания со стороны государства при проведении подобных реформ.

Ш. О’Брайен рассматривает результаты пересогласования условий членства Великобритании в ЕС и подчеркивает, что при проведении переговоров, также, как и при формировании политики в отношении ЕС в 2015-2016 гг. Д. Кэмерон не руководствовался результатами баланса компетенций, продемонстрировавших наличие баланса в компетенциях с союзом. Исследователь уделяет особое внимание тому факту, что баланс компетенций не получил широкой огласки, на него не ссылались в публикациях, размещавшихся на сайте правительства во время переговоров с ЕС.

Результаты исследования. Положение о балансе компетенций было закреплено в программе коалиционного правительства консерваторов и либерал - демократов в мае 2010 г. В разделе об отношениях с Европой говорилось, что на протяжении работы текущего парламента не произойдет дальнейшей передачи суверенитета или полномочий союзу. «Мы рассмотрим баланс существующих компетенций EC и, в частности, будем работать над ограничением применения Директивы о рабочем времени в Соединенном Королевстве» ${ }^{2}$. Впоследствии этот пункт программы был реализован в виде обширного исследования, о чем было сказано министром иностранных дел У. Хейгом в Палате Общин 12 июля 2012 г. «Кризис еврозоны усилил дискуссию во всех без исключений странах о будущем Европы. Сейчас самое время критически и конструктивно взглянуть на то, какие

\footnotetext{
${ }^{2}$ The Coalition: Our Programme for Government // The Coalition documentation, [Electronic resource]. URL : https://assets.publishing.service.gov.uk/government/uploads/system/uploads/atta chment_data/file/78977/coalition_programme_for_government.pdf (accessed : 06.04.2020). p. 19.
} 
именно полномочия принадлежат ЕС, какие - Великобритании, и работают ли они в наших национальных интересах» ${ }^{3}$.

Результаты исследования были изложены в отдельных отчетах. Они должны были быть непредвзятыми, нейтральными и фактическими. Министерство иностранных дел и по делам Содружества подчеркивало, что Обзор должен был быть аналитическим и включать в себя фактический материал. В отчетах не должно было содержаться выводов или рекомендаций относительно отношений Великобритании с ЕС, поскольку они были направлены на информирование гражданского общества о действительных отношениях Великобритании и $\mathrm{EC}^{4}$.

Термин «компетенция» как правило используется для описания способности ЕС предпринимать конкретные действия. В отношениях ЕС с государствами - членами существует три категории компетенций, впервые перечисленных в Лиссабонском договоре: исключительные компетенции, совместные компетенции, вспомогательные компетенции 5 . Для проведения Баланса компетенций было принято отличное от традиционного определение компетенции, охватывавшее «все области, в которых договоры наделяют ЕС правом действовать, включая положения договоров, наделяющие институты ЕС полномочиями принимать законы, принимать законодательные акты или предпринимать какие-либо другие действия» ${ }^{6}$.

Обзор проводился в течение четырех «семестров», каждый из которых содержал 6-10 отчетов по отдельным компетенциям. Перед публикацией каждого набора отчетов и для информирования их содержания ответственные государственные ведомства собирали доказательства, направляя запросы соответствующим заинтересованным сторонам и парламентским комитетам. Каждый доклад был посвящен отдельному аспекту компетенций, перечисленных в разделе I Догово-

\footnotetext{
${ }^{3}$ Review of the Balance of Competences between the United Kingdom and the European Union... p.5.

${ }^{4}$ Ibid

${ }^{5}$ The Balance of Competences Review in the United Kingdom, 2012-2014 // European Parliament [Electronic resource]. URL : http://www.europarl.europa.eu/RegData/etudes/BRIE/2016/573915/ EPRS_BRI(2016)573915_EN.pdf (accessed : 20.02.2020).p.1.

${ }^{6}$ The Review of the Balance of Competences between the UK and the EU // House of Lords [Electronic resource].URL : https://publications.parliament.uk/pa/ld201415/ldselect/ldeucom/ 140/140.pdf (accessed : 05.04.2020). p. 5-6.
} 
ра о функционировании Европейского Союза. Ко времени завершения обзора в декабре 2014 г. было опубликовано 32 доклада.

Фактический материал включал в себя как научные исследования, так и мнения заинтересованных сторон. Представленные сведения должны были быть объективной, фактической информацией о влиянии или эффекте действий ЕС в соответствующей области.

Большинство отчетов соответствовало предъявленным критериям объективности и непредвзятости. Некоторые работы, тем не менее, подверглись критике. Так, отчет в области полиции и уголовного правосудия был «Тщательно разграничен, чтобы не касаться вопросов, которые являлись предметом дискуссий об участии в них Великобритании» ${ }^{7}$. Замечание было сделано отчету в области расширенного сотрудничества и гибкости - его можно было бы рассмотреть систематически. Отдельно были указаны наиболее критиковавшиеся отчеты по свободному передвижению, рыболовному промыслу, здоровью животных и безопасности пищевых продуктов. Им не хватало сбалансированности и непредвзятости ${ }^{8}$.

Из 32 отдельных отчетов следует подробно рассмотреть отчеты по убежищу и иммиграционной политике в отношении государств, не входящих в союз, выплатам в бюджет ЕС и свободному перемещению по странам союза, поскольку именно по этим вопросам шло наиболее активное общественное обсуждение и выдвигались аргументы в пользу выхода Великобритании из ЕС.

Отчет по предоставлению убежища и иммиграционной политике в отношении стран, не входящих в союз, содержал информацию о пограничном контроле и процедуре предоставления убежища. В этой области в последние десятилетия отмечался рост компетенций ЕС 9 .

Великобритания не участвовала в Шенгенском пограничном кодексе, устанавливавшем контроль на внешних границах союза, и в Визовой информационной системе - базе данных, созданной для обеспечения безопасности. Вместе с этим она частично участвовала в Шенгенской информационной системе. Еще в 1985 г. Великобрита-

\footnotetext{
${ }^{7}$ The Review of the Balance of Competences between the UK and the EU... p.9.

${ }^{8}$ Ibid

${ }^{9}$ Review of the Balance of Competences between the United Kingdom and the European Union. Single Market: Free Movement of Persons // HM Government[Electronic resource]. URL : https://assets.publishing.service.gov.uk/government/uploads/system/uploads/attachment_data/file/3 35088/SingleMarketFree_MovementPersons.pdf (accessed : 06.04.2020).
} 
ния с Ирландией предпочли сохранить контроль на национальных границах, сославшись на свое островное географическое положение.

В сфере убежища и иммиграционной политики в Великобритании действовали специальные положения, в соответствии с которыми она была связана только правовыми актами ЕС, в которых она решила участвовать. В случае, если страна отказывалась присоединиться к определенному соглашению, она могла сделать это позже, т.е. сохранить за собой право участия/неучастия.

Взаимодействие Великобритании с ЕС в сфере миграции и предоставления убежища заключалось в комплексе соглашений, в рамках которых Великобритания согласовала статус-кво, характеризующийся крупномасштабными неучастием, а также различными продолжающимися вариантами участия, что демонстрировало сочетание избирательности и гибкости. В обзоре сообщалось, что Великобритания решила принять примерно одну треть мер ЕС в области предоставления убежища и иммиграционной политики, однако их количество снижалось, поскольку ЕС расширял свою деятельность. Возможность участия/неучастия Великобритании в соглашениях позволяли ей последовательно корректировать отношения с ЕС. Это означает, что государство могло в одностороннем порядке выбирать свою оптимальную политику и время от времени незначительно изменять ее. Эта избирательность и гибкость рассматривались как привилегия Великобритании, так как распространение этой практики на остальные государства - члены ЕС сделало бы систему ЕС неработоспособной, угрожая ее распаду. В обзоре отмечалось, что компетенции по иммиграции и убежищу принадлежали главным образом Великобритании, и правительство не намерено было менять этот порядок. Обзор концентрировался на оценке того, соответствуют ли британские изъятия (opt-outs) и специальные положения национальным интересам. И, несмотря на финансовые издержки, связанные с пограничным контролем, они компенсировались усиленной безопасностью на границе ${ }^{10}$.

Выплаты в бюджет ЕС были одним из аргументов в пользу выхода Великобритании из ЕС. Сторонники Брексита утверждали, что взнос страны в бюджет ЕС является одним из крупнейших и часто

\footnotetext{
${ }^{10}$ British Balance of Competence Reviews, Part II // European Policy Institutes Network [Electronic resource]. URL : https://epin.org/wp-content/uploads/2019/02/EPIN_40-B-o-C-Part-IIformatted-final-rev-27.5.14-final.pdf (accessed : 04.04.2020).
} 
превышает взносы таких стран, как Италия и Франция. Эти средства, как утверждалось, разумнее было бы потратить на образование и систему здравоохранения ${ }^{11}$.

Рассматривая выплаты Великобритании в бюджет ЕС, следует отметить, что он расходовался на сельское хозяйство, структурные фонды, внешнюю политику и науку ${ }^{12}$. Когда сторонники Брексита говорили о выплатах в бюджет, составлявших, по их подсчетам, 350 млн ф ст. в неделю - что не соответствовало действительности- они не учитывали тот факт, что часть средств возвращается государству в рамках специальной компенсации ${ }^{13}$.

Компенсация возвращала Великобритании значительную часть ее чистого вклада в бюджет. Впервые компенсации были введены в 1973-74 гг., когда государство договаривалось с ЕС о специальных условиях членства.

В то время в структуре расходов бюджета преобладали расходы на сельское хозяйство, а относительно небольшой размер британского сельскохозяйственного сектора привел к тому, что Великобритания платила самую высокую сумму чистых взносов на душу населения.

С течением времени и изменением структуры расходов компенсация, или «корректирующий механизм», был пересмотрен, став более сложным, поскольку и другие крупные плательщики также хотели получить определенную компенсацию.

Обзор показал, что в 2012 г. Великобритания получила наименьшую сумму расходов ЕС на душу населения из всех стран членов ЕC, и что ее чистый вклад в бюджет до компенсации был соответственно самым высоким ${ }^{14}$. После компенсации чистый взнос

\footnotetext{
${ }^{11}$ Cost of the EU - let's spend our money on our priorities // Vote Leave [Electronic resource]. URL : http://www.voteleavetakecontrol.org/briefing_cost.html (accessed : 20.02.2020).

12 EU Budget 2012 Financial Report // European Commission [Electronic resource]. URL : https://ec.europa.eu/budget/financialreport/2012/pdf/financialreport-2012_en.pdf (accessed 06.04.2020).

${ }^{13}$ Why Vote Leave's $£ 350 \mathrm{~m}$ weekly EU cost claim is wrong // The Guardian [Electronic resource]. URL : https://www.theguardian.com/politics/reality-check/2016/may/23/doe-the-eu-really-cost-theuk-350m-a-week (accessed : 06.04.2020).

${ }^{14}$ British Balance of Competence Reviews, Part III // European Policy Institutes Network [Electronic resource].URL : https://www.researchgate.net/profile/Miroslav_Beblavy/publication/280225 498_British_Balance_of_Competence_Reviews_Part_III_More_reform_than_renegotiation_or_rep atriation/links/55ae0af308ae98e661a466e1/British-Balance-of-Competence-Reviews-Part-IIIMore-reform-than-renegotiation-or-repatriation.pdf (accessed : 04.04.2020).
} 
Великобритании в бюджет ЕС был четвертым по величине и составил $12,5 \%$ от бюджета $\mathrm{EC}^{15}$.

Составителями отчета приходят к выводу, что в сфере выплат Великобритании в бюджет ЕС баланс компетенций являлся оптимальным, его можно было улучшить путем реформирования структуры бюджета и совершенствованием финансового управления бюджетом ЕС в государствах - членах и институтах $\mathrm{EC}^{16}$.

Вопрос свободного перемещения в странах ЕС - иммиграция из других государств - членов ЕС в Великобританию - стал одним из основных аргументов в пользу выхода Великобритании из ЕС [1, с. 14]. Британцы считали, что существующая система свободного перемещения граждан ЕС не сбалансирована и требует пересмотра. Тем не менее, ограничение иммиграции из государств - членов ЕС противоречило бы одному из основополагающих принципов ЕС принципу свободного передвижения.

В отчете указывается, что за последнее десятилетие произошел существенный сдвиг общественного мнения в сторону неприятия иммигрантов. Социологический опрос You Gov демонстрирует, что почти половина населения была против принципа свободного передвижения в 2013 г., в то время как в 2005 г. две трети выступали за него ${ }^{17}$.

Негативное восприятие иммиграции в Великобритании было сформировано в начале 2000-х, и было связано с ее отказом в 2004 г. ограничить доступ к своему рынку труда для граждан государств, присоединившихся к $\mathrm{EC}^{18}$. Введение же переходного периода с ограничением доступа к рынку труда, как это было сделано в последующие расширения ЕС, уменьшило бы приток трудовых иммигрантов и не вызвало бы такой общественной реакции. Негативное отношение к миграции также было обусловлено тем, что в период с 2004 по 2012 гг. количество живущих в Великобритании граждан других государств-членов ЕС более чем удвоилось - с 1,1 млн до 2,3 млн ${ }^{19}$. В связи с этим в начале 2000-х недовольство британцев мигрантами сместилось с граждан государств Содружества Наций на граждан ЕC,

\footnotetext{
${ }^{15}$ EU Budget 2012 Financial Report...

${ }^{16}$ British Balance of Competence Reviews, Part III... p.14.

${ }^{17}$ Ibid, p.8.

${ }^{18}$ Ibid, p. 7.

${ }^{19}$ British Balance of Competence Reviews, Part III... p.7.
} 
прибывающих в Великобританию из стран с более низким уровнем жизни [2, с. 51], а обсуждение отношений с ЕС стали связаны в основном с иммиграцией [3, с. 1144].

В начале 2014 г. количество въехавших в Великобританию из государств - членов ЕС впервые превзошло количество впервые прибывших в Соединенное Королевство из других государств.

Рассматривая вопросы идентичности, следует отметить, что британцы неохотнее жителей других государств ЕС идентифицировали себя как «европейцы», что демонстрировало их некоторую отчужденность от континентальной Европы. Правительство Великобритании было недостаточно вовлечено в регулирование миграции из стран ЕС по причине того, что государство не входило в Шенгенскую зону и имело некоторые изъятия из законодательства ЕС в области миграции и предоставления убежища [3, с. 1139].

Отчет о свободном передвижении в ЕС сообщает о ряде фактов, свидетельствующих в его пользу. Иммигранты вносили вклад в общество: платили налоги и тратили заработанные деньги преимущественно на внутреннем рынке Великобритании. Более того, они меньше обращались за государственными услугами - включая национальную систему здравоохранения. Также упоминается, что около $60 \%$ иммигрантов уже имели предложения о работе, прибывая в страну. Было указано, что преимуществом свободного передвижения пользуются и граждане Великобритании, живущие за границей, например, пенсионеры в Испании и Франции, и как работает система социальных гарантий ЕС в данном случае. В Соединенном Королевстве насчитывалось около 13,4\% исследователей из выходцев других государств - членов ЕС. Данные о выплачиваемых иммигрантами налогах и их нечастым обращением к государственным услугам сместили фокус дискуссий против иммиграции из стран ЕС с финансовых соображений на нагрузку на систему образования, проблемы жилья и экспорт пособия на ребенка за границу ${ }^{20}$. Этот переход был отражен в переговорах по пересмотру условий членства Великобритании в ЕС в 2015-2016 гг. ${ }^{2122}$.

\footnotetext{
${ }^{20}$ Review of the Balance of Competences between the United Kingdom and the European Union. Single Market: Free Movement of Persons... p.7-8.

${ }^{21}$ The Future of Britain's Relationship with the EU (Transcript) // Chatham House [Electronic resource]. URL : https://www.chathamhouse.org/sites/files/chathamhouse/events/special/20151110 DavidCameron\%20\%28NEW\%29.pdf (accessed : 06.04.2020). p. 7-8.
} 
Отчет о свободном передвижении в ЕС критиковался за несбалансированность, поскольку много внимания в нем уделялось критике свободного передвижения - на это была выделена глава 3 отчета ${ }^{23}$, в то время как свидетельств негативного его влияния на национальные интересы Великобритании было немного, они были представлены в основном исследовательскими центрами Open Europe и Demos. Итоговый отчет подчеркивал недостаточность указанных критических свидетельств и их схожесть с официальной позицией правительства, и отмечал, что выводы Главы 3 вытекали из малого числа фак$\operatorname{TOB}^{24}$.

Баланс компетенций между Великобританией и ЕС - масштабное исследование, результаты которого так и не стали известны широким кругам, могли помочь сформировать правильное представление об отношениях между Великобританией и ЕС в обществе.

Результаты исследования опровергали имевшиеся опасения относительно увеличивавшегося влияния ЕС на дела Великобритании. По трем основным пунктам, которые были аргументами в пользу выхода страны из ЕС - иммиграции и предоставлению убежища, выплатам в бюджет ЕС и свободному передвижению - авторы отчетов баланса компетенций пришли к выводу, что Великобритания обладала достаточными компетенциями в данных областях и извлекала из этого определенную выгоду.

Тем не менее, Д. Кэмерон не руководствовался итогами баланса компетенций перед тем, как делать публичные заявления по внешней политике в отношении ЕС, как это произошло в январе 2013 г., когда он выступил с речью, в которой пообещал провести референдум о членстве Великобритании в ЕС в случае победы консерваторов на следующих всеобщих выборах, не позднее 2017 г. $^{25}$. Позже была предпринята неуспешная попытка закрепить данное обещание в Бил-

\footnotetext{
${ }^{22}$ European Council conclusions, 18-19 February // Council of the European Union [Electronic resource. URL : https://www.consilium.europa.eu/media/21787/0216-euco-conclusions.pdf (accessed : 06.04.2020).

${ }^{23}$ Review of the Balance of Competences between the United Kingdom and the European Union. Single Market: Free Movement of Persons...p.53-59.

24 The Review of the Balance of Competences between the UK and the EU... p. 11.

${ }^{25}$ EU speech at Bloomberg // The UK Government [Electronic resource]. URL : https://www.gov. uk/government/speeches/eu-speech-at-bloomberg (accessed : 15.04.2020).
} 
ле о референдуме (2013-2014 гг.) ${ }^{26}$. Критика ЕС, призывы реформировать союз продолжились. Более того, в 2011-2014 гг., параллельно с ходом исследования иммиграции коалиционным правительством принимались меры по ее ограничению [4]. Речь шла только об ограничении внешней иммиграции, поскольку принцип свободного перемещения в ЕС позволял гражданам других государств-членов беспрепятственно прибывать в Великобританию, и правительство не могло что-либо предпринять для ограничения въезда граждан ЕС. А в марте 2014 г. в статье газеты Telegraph Д. Кэмерон уже выдвигал идеи по реформе ЕС, говоря, что «я полностью понимаю и разделяю озабоченность людей по поводу Европейского Союза. Наши предприятия ценят единый рынок. Но они считают степень европейского вмешательства в нашу повседневную жизнь чрезмерной» ${ }^{27}$.

Обсуждение полученных результатов. Таким образом, выводы исследования отношений между Великобританией и ЕС, определившие их компетенции и степени влияния ЕС на Соединенное Королевство были менее важны, чем антиевропейские тактические ходы для поддержки внутрипартийной целостности и соперничества с Партией независимости Соединенного Королевства.

Премьер-министр действовал в соответствии со складывающимися обстоятельствами, но эти действия не основывались на объективных данных и служили для достижения краткосрочных политических целей. Пренебрежение запущенным им самим балансом компетенций также показывает, что данное исследование, во-первых, было начато не с целью получить объективные факты о текущем положении дел между Великобританией и ЕС, а для того, чтобы продемонстрировать ЕС необходимость изменения двусторонних отношений и высказать опасения, что союз угрожает суверенитету Соединенного Королевства; во-вторых, из-за ожиданий Д. Кэмерона относительно результатов данного исследования - из его заявлений следовало, что Великобритания делегировала ЕС слишком много полномочий и что пора вернуть их обратно ${ }^{28}$ [20]. Премьер - министр рассчитывал, что

\footnotetext{
${ }^{26}$ European Union (Referendum) Bill // The UK Parliament [Electronic resource]. URL : https:// services.parliament.uk/Bills/2013-14/europeanunionreferendum.html (accessed : 15.04.2020).

${ }^{27}$ David Cameron: the EU is not working and we will change it // The Telegraph [Electronic resource]. URL : https://www.telegraph.co.uk/news/newstopics/eureferendum/10700644/DavidCameron-the-EU-is-not-working-and-we-will-change-it.html (accessed : 15.04.2020).

${ }^{28}$ David Cameron promises in/out referendum on EU // British Broadcast Company [Electronic resource]. URL : http://www.bbc.com/news/uk-politics-21148282 (accessed : 06.04.2020).
} 
баланс компетенций это подтвердит, - однако его ожидания не оправдались, и это могло стать причиной недостаточного освещения результатов отчетов [5]. Следовательно, действия Д. Кэмерона в отношении ЕС в 2013-2014гг. и последовавший за этим пересмотр условий членства в ЕС не основывались на полученных в результате баланса компетенций данных. Отчеты так и не получили широкой огласки и не были использованы для формирования политики Соединенного Королевства в отношении ЕС.

Выводы. 1. Баланс компетенций между Великобританией и ЕС в областях предоставления убежища, иммиграционной политики в отношении государств, не входящих в союз, выплат в бюджет EC, a также свободного перемещения по странам союза показал преобладание британской компетенции над компетенцией ЕС и соответствие интересам государства. 2. Результаты исследования не получили широкой огласки и не использовались премьер-министром Д. Кэмероном для корректировки политики в отношении ЕС, поскольку первоначально предполагалось, что большое количество компетенций принадлежит ЕС, а баланс компетенций должен был это подтвердить, закрепив тем самым ужесточение курса в отношении союза со стороны коалиционного правительства.

\section{Библиографические ссылки}

1. Portes $J$. Immigration, Free Movement and the EU Referendum. National Institute Economic Review, 2016. № 236. P. 14-22.

2. Хахалкина E.В. Иммиграционная политика Д. Кэмерона (2010-2015 гг.). Современная Европа, 2015. №4 (64). С. 47-58.

3. Dennison J., Geddes, A. Brexit and the perils of 'Europeanised' migration. Journal of European Public Policy. 2018. Vol. 25. №8. P. 1137-1153.

4. Robinson D. Migration policy under the coalition government. People, Place and Policy. 2013. Vol. 7. №2. P. 73-81.

5. O'Brien C. Cameron's renegotiation and the burying of the balance of competencies review // The UK in a changing Europe [Electronic resource]. 2016. URL :https://ukandeu.ac.uk/cameronsrenegotiation-and-the-burying-of-the-balance-of-competencies-review/ (accessed: 12.03.2020).

Дата поступления статьи: 17.11.2020.

Автор: Пашковская Елена Олеговна - аспирант кафедры международных отношений Белорусского государственного университета (Минск); e-mail: yelena.pashkovs@gmail.com. 


\title{
BALANCE OF COMPETENCES BETWEEN THE UK AND THE EU: RESULTS AND IMPLICATIONS FOR A POLICY OF THE UNITED KINGDOM
}

\author{
A. O. PASHKOUSKAYA \\ Belarusian State University \\ Minsk, Republic of Belarus
}

\begin{abstract}
The article discusses a study of the balance of competences with the European Union (EU), carried out in 2012-2014 in the UK, its results and impact on UK policy towards the EU. The purpose of the article is to analyze the results of a study initiated by the UK government and its impact on state's policy towards the EU. The following areas of joint competence between the United Kingdom and the EU were selected for consideration: asylum and immigration policy towards non-EU states, payments to the EU budget, free movement within the Union countries. The author carried out a critical analysis of reports in these areas, revealed the degree of their significance in the formation of UK policy towards the EU. This study is one of the first studies to address the issues of competence analysis between the UK and the EU in Russian-language historiography. The author notes that in the field of immigration, free movement and payments to the EU budget, the study showed the prevalence of British competence and compliance with the interests of the state. Nevertheless, D. Cameron did not take into account the results of the study for making foreign policy decisions, and the balance of competences was initiated not to obtain objective facts about the current state of affairs between the UK and the EU, but only to demonstrate British intentions to change relations with the EU. The results of the balance of competencies were not taken into account in the foreign policy towards the $\mathrm{EU}$, and also did not become known to the general public, which demonstrated the discrepancy between the objectives of the study and the decisions of the government.
\end{abstract}

Key words: United Kingdom; European Union; balance of competences; coalition government; Brexit; Conservative party; David Cameron; immigration; free movement; asylum system.

For citation: Pashkouskaya, A. (2020). Balance of Competences between UK and the EU: Results and implications for a policy of the United Kingdom (2012-2014). In: Actual problems of international relations and global development: collection of 
scientific papers. Minsk, Vol. 8, p. 88-102. https://doi.org/10.33581/2311-94702020-8-88-102

\section{References}

1. Portes, J. (2016). Immigration, Free Movement and the EU Referendum. In: National Institute Economic Review. № 236. p.14-22.

2. Khahalkina, Y. V. (2015). Immigracionnaya politika D. Kemerona (2010-2015 gg.). [Immigration policy of D. Cameron (2010-2015)]. In: Contemporary Europe. №4 (64). p. 47-58. (In Russ.). 3. Dennison, J., Geddes, A. (2018). Brexit and the perils of 'Europeanised' migration. In: Journal of European Public Policy. Vol. 25. №8. p. 1137-1153.

4. Robinson, D. (2013). Migration policy under the coalition government. In: People, Place and Policy. Vol. 7. № 2. p. 73-81.

5. O'Brien, C. (2016). Cameron's renegotiation and the burying of the balance of competencies review // The UK in a changing Europe [Electronic resource]. URL :

https://ukandeu.ac.uk/camerons-renegotiation-and-the-burying-of-the-balance-of-competenciesreview/ (accessed: 12.03.2020).

Received: 17.11 .2020 .

About author: Pashkouskaya Alena, Master of Historical Sciences, a postgraduate student of the Department of international relations of Belarusian state University (Minsk); e-mail: yelena.pashkovs@gmail.com. 